\title{
Relatório Anual dos Editores, 1991
}

Em 1991, a Revista de Saúde Pública completou um quarto de século de existência. Conforme foi programado para registro desta data, seis artigos, encomendados a especialistas, sobre temas diversos e atuais, foram editados na Revista de Saúde Pública, em cada um dos fascículos do ano. Tais artigos, de autoria de especialistas a seguir nominados, versaram sobre: "A engenharia genética", de J.A.N. Candeias; "Qualidade de vida e meio urbano", de Oswaldo Paulo Forattini; "Agricultural development and arthropod-bome diseases: a review", de M.W. Service; "On the economic analysis of response to preventive measures", de R.F. Iunes; "Da medicina do trabalho à saúde do trabalhador", de R. Mendes \& Elizabeth Costa Dias; "Análise da informação em saúde: 1893-1993", de R. Laurenti.

Quanto aos artigos submetidos à publicação, num total de 113, o Conselho de Editores aprovou 65, representando $57,5 \%$ do total. Assim, pois, o indice de recusa alcançou $42,5 \%$ (em 1990 foi de $38,9 \%$ ) (Tabela 1).

Tabela 1. Manuscritos submetidos à publicação e julgados em 1991.

\begin{tabular}{lc}
\hline Manuscritos & Ne \\
\hline Recebidos em 1989 & 4 \\
Recebidos em 1990 & 41 \\
Recebidos em 1991 & 122 \\
Total & 167 \\
Julgados & 113 \\
Em processo de julgamento & 54 \\
Resultado do julgamento & \\
$\quad$ Aceitos & $14(12,4 \%)$ \\
$\quad$ Aceitos com modificaçōes de pequena monta & $9(8,0 \%)$ \\
Aceitos sob condição & $42(37,2 \%)$ \\
$\quad$ Recusados & $38(33,6 \%)$ \\
Recusados com possibilidade de reapresentação & $10(9,2 \%)$ \\
\hline
\end{tabular}

Nos seis fascículos do ano foram publicados 70 artigos, sendo 52 originais de pesquisa $(74,3 \%)$, em concordância, portanto, à política editorial adotada pela Revista. Outros 18 artigos, classificados em revisão e atualização e notas e informações, completam o total publicado (Tabela 2). Quanto a outro tipo de matéria, esclarece-se que se encontra em reformulação a Seção de "Resumos de Livros", com o objetivo de adequá-la a um tipo de contribuição mais apropriada ao leitor, na linha de resenhas críticas.

Tabela 2. Matéria publicada segundo sua classificacăo, por tipo, 1991*.

\begin{tabular}{lrr}
\hline \multicolumn{1}{c}{ Matéria } & No & $\%$ \\
\hline Artigos & & \\
Pesquisas original & 52 & $74,3 \%$ \\
Revisão & 2 & $2,8 \%$ \\
Atualização & 11 & $15,8 \%$ \\
Atualidades & 1 & $1,4 \%$ \\
Notas e informaçōes & 4 & $5,7 \%$ \\
Total de artigos & 70 & $100,0 \%$ \\
Outras matérias & & \\
Editorial & 3 & \\
Carta ao Editor & 1 & \\
Relatório da RSP & 1 & \\
Matéria publicada nos volumes 24(6), 1990 25(1-5), 1991 & \\
Trabalhos encomendados & \\
Dois trabalhos encomendados & &
\end{tabular}


No que se refere à temática dos artigos publicados, $57,1 \%$ deles foram classificados em Epidemiologia, seguida de Administraçāo e Serviços de Saúde, com $22,9 \%$, sendo que Saúde Ambiental, Demografia e Nutrição completam a temática, com $20 \%$ dos artigos.

Quanto à origem geográfica dos locais de realização dos trabalhos, o Estado de São Paulo continua na frente, a exemplo de anos anteriores, com 67,1\% do total publicado (47 artigos). Os outros Estados foram representados por autores do Rio de Janeiro, Minas Gerais, Pernambuco, Bahia, Maranhảo, Goiás e Paraná. Os artigos originários do exterior, num total de 7, são de autores do Chile, Cuba, Inglaterra, Panamá, Canadá, Argentina e Estados Unidos da América do Norte.

A distribuição da Revista, feita sobretudo por venda de assinaturas e por permuta, vem se mantendo, sendo que no primeiro caso (vendas) tem-se observado queda nestes últimos anos, confirmada também em 1991. Quanto à permuta, são 256 títulos recebidos (140 estrangeiros e 116 nacionais) e incorporados ao acervo da Biblioteca da Faculdade de Saúde Pública, que representam um investimento da ordem de US\$ 3,500.00 anuais. Por outro lado, a questão dos custos dessa distribuição, em relação às despesas postais, está se caracterizando como problema de difícil administração. No entanto, solução está sendo buscada para que os leitores e autores não fiquem ainda mais prejudicados com a demora na divulgação dos resultados das pesquisas, pelo atraso na distribuição dos fascículos.

A questão dos recursos para publicação foi praticamente sanada em 1991, sobretudo pela nova modalidade de concessão de aux́lio feita pela FAPESP pelo seu "Programa de financiamento de artigos provenientes de pesquisadores do Estado de São Paulo", no qual a Revista está incluída.

A FINEP, por sua vez, juntamente com a Comissão de Credenciamento da Univesidade de São Paulo, concedeu-nos os recursos complementares. Aquela (FINEP), inclusive, contribuiu com recursos para despesas postais, como complemento aos recursos da Faculdade de Saúde Pública destinados para esta finalidade, garantindo assim a distribuiçāo dos seis números anuais, embora com certo atraso.

O Conselho de Editores esteve constituído, em 1991, pelos seguintes membros:

Prof. Dr. Oswaldo Paulo Forattini (Editor)

Prof. Dr. André Jacquemin - Editor Associado

Prof. Dr. Diogo Pupo Nogueira - Editor Associado

Prof. Dr. José Alberto Neves Candeias - Editor Associado

Profa. Dra. Maria José Roncada - Editor Associado

Prof. Dr. Nagib Haddad - Editor Associado

Prof. Dr. Naomar de Almeida Filho - Editor Associado

Profa. Maria Teresinha Dias de Andrade - Editor Assistente

Nesta oportunidade deixamos expresso aqui os agradecimentos às instituições acima mencionadas, que subvencionaram a publicação da Revista, sem o qual não teria sido atingida nossa meta de publicação. Agradecemos também à equipe técnica e administrativa da Revista, pela eficiência demonstrada. Aos relatores apresentamos o nosso especial reconhecimento pelo trabalho de análise realizado, com as judiciosas revisōes que sem dúvida contribuíram para que a Revista de Saúde Pública pudesse manter seu padrão de qualidade e continuar a ser registrada pelos principais centros de disseminação da informação técnica e científica especializada, nacional e internacional.

São Paulo, junho, 1992.

Conselho de Editores. 